\title{
Measurement of Rural Residents' Mobility in Western China: A Case Study of Qingyang, Gansu Province
}

\author{
Chunfang Liu ${ }^{1, *}$, Bin $\mathrm{Yu}^{2}$, Yue Zhu ${ }^{3}$, Licheng Liu ${ }^{2}$ and Pengjie $\mathrm{Li}^{2}$ \\ 1 College of Social Development and Public Administration, Northwest Normal University, \\ Lanzhou 730070, China \\ 2 College of Geography and Environmental Science, Northwest Normal University, Lanzhou 730070, China; \\ 18893707702@163.com (B.Y.); llcnwnu@163.com (L.L.); peng1154801439@163.com (P.L.) \\ 3 Women's Federation of Qingyang City, Qingyang 745000, China; qysfegwb@163.com \\ * Correspondence: liuchunfang@nwnu.edu.cn; Tel.: +86-0931-7971565
}

Received: 28 February 2019; Accepted: 22 April 2019; Published: 28 April 2019

check for updates

\begin{abstract}
Mobility is a popular topic in the fields of humanities and social sciences. China's rapid urbanization has resulted in the acceleration of urban-rural mobility. Moreover, the implementation of the New Urbanization and Rural Revitalization Strategy has demonstrated the prospects of urban-rural integration and development. However, research on rural mobility is mainly focused in the fields of economics and sociology, with insufficient attention paid to spatial mobility. The main purpose of this study is to introduce a new theoretical explanation of the four dimensions of rural mobility based on a complete understanding of the current socio-economic background, namely, network mobility, green mobility, people-oriented mobility, and smart mobility. On this basis, a rural mobility evaluation index system is proposed by attempting to build a synthetic rural mobility index from the four aforementioned dimensions. Qingyang, a typical city in Western China located in the Loess Hilly Region, is taken as an example. Accordingly, the comprehensive rural and four-dimensional mobilities are analyzed and evaluated, and the effectiveness of the index system is verified. Results show that Qingyang's rural mobility is at a low level, but differences in the types of rural residents, districts and counties, and dimensions of mobility are observed. At the end of this paper, the inclusion of mobility promotion in the policy system of rural revitalization is emphasized.
\end{abstract}

Keywords: Loess Hilly Region; rural residents; daily activities; mobility; measurement

\section{Introduction}

In the past decade, mobility has been an important research field in social sciences and human geography. People currently live in the "Age of Migration" [1] and "Worlds of Motion" [2]. From agricultural to industrial society and from post-industrial to the rising smart society, mobility has always been the organizational form of daily activities of human society. Mobility is essential for human survival and development. It helps to define the structure of people's lives and quickly becomes a formative element of existence [3]. The role of mobility is thus crucial to the understanding of modern urban life. Castells coined the term "space of flow" based on the interaction between cyberspace and geographical space [4]. Lash and Urry also argued that modern society is a society on the move [5]. With the development of human society, changes in family structure, employment mode, social networks, and urban space will make the daily life of urban residents increasingly complex [6].

The importance of mobility exists in cities and rural areas. As Bracey said, "Mobility and migration hold the key to the future of the countryside" [7]. Mobility has always been an important driving force for rural changes, which can be found in the flow of population and other factors between urban and rural areas. However, compared with the mobility of cities, the mobility of rural areas remains 
at a low level of development. Many geographic studies on mobility still focus on cities and take "cities" as the prototype space of super-mobility. Moreover, less attention has been provided to rural mobility [8]. Nevertheless, the spread of informatization from urban to rural areas has introduced new opportunities for rural development, such as "Mobility as a Service", which is one of the novel mobility concepts that can assist in achieving seamless mobility [9].

China's rapid urbanization has attracted worldwide attention. This urbanization not only promotes urban economic growth but also accelerates urban-rural mobility [10-12]. However, mobility in China's rural areas is low because of farmers' livelihood difficulties, inadequate public services, and the outflow of young and middle-aged workers [13], especially in Western China. Nevertheless, the New Urbanization and Rural Revitalization Strategy promoted by the central government in recent years implies that China's urbanization development has entered a new stage. This strategy initially focused on economic growth and land development and then moved towards people-oriented social space construction. Simultaneously, the Rural Revitalization, a new national strategy, has become an important driving force that affects urban and rural socio-economic development and their spatial patterns. Informatization is also proposed in the Rural Revitalization Strategy as an important means for promoting rural development. Current policies are changing the social and spatial mobility characteristics of rural residents of China. In the future, livelihood-oriented mobility will no longer be the sole mode, and the pursuit of a better quality of life as well as the urban demand for labor force will jointly promote the increasingly complex mobility of rural residents.

Most of the existing spatial mobility studies generally focus on cities rather than rural areas. The research on rural mobility is still relatively inadequate, and there is even less regarding the use of the framework of a smart city to consider and evaluate the mobility of rural areas. Especially in the rural areas of Western China, discussing the need for an integrated "smart" mobility scheme to comprehensively incorporate the various activities of urban and rural residents is necessary. Meanwhile, the exploration of the mobility evaluation of rural residents in Western China is necessary for the theoretical innovation and practical exploration of rural geography research in China. This study aims to provide an all-inclusive explanation of rural mobility and to propose a feasible concept of synthetic people-oriented mobility on the basis of a new understanding of the current mobility of rural residents in China. This will allow the current socio-economic and technological background to be better matched and the needs of people-oriented urban and rural planning and construction to be addressed. The present study also attempts to build a comprehensive evaluation index system and measure the mobility level in Western China.

This paper is organized as follows. The next section reviews the literature on rural mobility. Section 3 discusses the methodology, including the connotations of rural mobility and appropriate indicators to evaluate rural mobility. Section 4 applies the methodology to the case area and presents the feasibility of the proposed index and analysis of the obtained results. Finally, this paper offers some conclusions and future lines of research.

\section{Literature Review}

Although mobility involves many aspects, such as society, economy, and space, it is geographic in nature. Thus, the movement of people and things across time and space as well as the process of creating places are important parts of mobility. As mobility plays an increasingly important role in space and social organization, it has gradually become an important geographic issue [14]. According to Urry, "places are economically, politically and culturally produced through the multiple mobilities of people, but also of capital, objects, signs and information" [15]. Many human geographers have emphasized the importance of infrastructure, the building environment, and daily activities to mobility $[16,17]$, and have also considered mobility as a process of actively shaping or producing complex and dynamic spaces [18]. Different types of flow elements have continuously changed and shaped the relationship between urban and rural areas and regional spatial patterns. 
Mobility is usually defined as the movement of people from one place to another and is measured as the number of trips or the distance travelled per day. Some authors consider the trips at the annual level [19] or by the frequency of activities [20]. Spatial mobility includes factors related to access, skills, personal expectation, acquired knowledge, and cognitive appropriation [3]. In addition to explaining social mobility, Urry distinguished five different types of travel [15]. Brighenti proposed an environmental sociology of urban motilities comprising a threefold exploration-a dromology of displacement, a rhythm analysis of flow, and an affectology of travel [21]. By distinguishing daily and non-daily spatial mobility [22], Kellerman divided daily spatial mobility into two categories, namely, corporeal and virtual mobilities, in accordance with three intrinsic "push" factors (locomotion, proximity, and curiosity) and several external "pull" factors (employment, shopping, and entertainment) [23].

Scholars in the fields of human and transportation geography recently began to explore the experience of mobility and affective atmospheres of travel. Such atmospheres include perceptions of comfort, discomfort, satisfaction degree, and ambiance in which travel unfolds, as well as the meanings and significance attributed to experienced mobilities [24-28]. With the increasingly serious problems of congestion, traffic accidents, and pollution, future mobility is also facing many challenges. Recently, the sustainable mobility approach was proposed, which requires actions to reduce the need to travel (less trips), encourage modal shift, minimize trip lengths, and encourage considerable efficiency in the transport systems [29]—including green travel [30-33]. The ecological impact of mobile behaviors was also considered [34]. A similar concept is smart urban mobility, which can be perceived as "a set of coordinated actions addressed at improving the efficiency, the effectiveness and the environmental sustainability of cities" [35]. Although no consensus on smart mobility exists, scholars all emphasize affordable, effective, attractive, and sustainable connectivity $[29,36]$.

Mobility is an important and essential component of rural lifestyle and rural areas. Rural socio-economic development and mobility have constantly been the focus of academic attention, involving mobility and activities in different fields, such as socio-economic space $[8,37,38]$, especially in the economically backward areas of developed or developing countries. Early studies focused on the nature and characteristics of rural occupational change and mobility [39], different patterns of rural mobility [40], and changes from the "traditional" to "modern" travel behavior patterns [41]. A comparative study of travel behaviors between rural and urban areas in the United States showed that the former generally had a higher level of mobility than the latter. This finding is attributed to the dispersed housing and activities in rural areas, which increase travel distances and force people to rely on cars [42].

In recent years, research on mobility has classified rural residents [43], studied the travel behaviors of rural middle-class residents [44], and explained typical rural activity patterns, decision-making procedures, and travel chain characteristics [45] by using data of rural residents' activities and travel characteristics. Some scholars also compared the time variation of urban and rural residents' travel behaviors [46,47] and the differences in sports and leisure behaviors [48]. With the increasing interaction between urban and rural areas, Jerry Olsson explored how the long-distance mobility behaviors of households and individuals has changed over a period [49]. Meanwhile, the increased importance of rural virtual mobility via cyberspace is emphasized [14], which is a new but potential issue for rural area mobility research.

The existing literature focuses on the mobility of "vulnerable groups of transportation" in rural areas, especially the poor, elderly, and disabled. Scholars have explored the mobility of different types of people, including young residents [50], the elderly, the disabled, women, and other vulnerable groups in rural areas [51-54]. Research shows that making a living is the most common purpose of short-distance travel for all income groups and regions [55]. Poor and middle-income urban and rural residents benefit from the use of a variety of public transport modes. For these groups, food shops, health centers, and financial institutions-such as post offices and banks-are the most common "necessary" trip destinations [19,56]. 
Compared with foreign studies, few studies have focused on the spatial mobility of rural residents in China. Previous research has paid extra attention to rural-urban migrants promoted by rapid urbanization and industrialization [57], with emphasis on the importance of mobility strategies that consider the specific needs within the field of rural transportation [43]. Recent studies have focused on the impact of rural human capital and China's forest conservation programs on rural residents' mobility $[11,12,58]$. Human geographers emphasize the importance of building an analytical framework for urban-rural integration on the basis of factor flow [59].

\section{Methodology}

\subsection{Case Area}

The Loess Hilly Region is a typical ecologically fragile area in Western China. It is an area with a large number of poor people and prominent environmental problems represented by ecological degradation [60]. Accordingly, Qingyang City was selected as the case study area (Figure 1). The city is located in the Loess Hilly Region of Western China, also in the eastern part of Gansu Province and the intersection of Shaanxi Province, Gansu Province, and the Ningxia Hui Autonomous Region. It covers an area of 27,119 $\mathrm{km}^{2}$, including Xifeng, Qingcheng, Huanxian, Huachi, Heshui, Ningxian, Zhengning, and Zhenyuan's eight counties (districts). Qingyang City is one of the birthplaces of agriculture in China. Traditional agriculture is the main resource-based industry, but it has a weak industrial foundation. At the end of 2016, the city's GDP was only 59.783 billion yuan, and the per capita disposable income of rural residents was 7480 yuan, far below the national average. By the end of 2016, the total population of the city was 2.6498 million, of which 1.8654 million were from rural areas. Moreover, the urbanization rate of the permanent population was $34.99 \%$, which was lower than the average level for the entire country and province.

In recent years, with the improvement of rural productivity brought about by the development of agricultural mechanization, a large surplus labor force has outflowed from Qingyang City in search of livelihood. Notably, Qingyang City has the largest outflow of people in Gansu Province. Generally, to increase income and improve life, the flow of rural residents in Qingyang City shows the following obvious characteristics-old people farm, young people go out to work, and the rest live close to farming or planting areas. In addition, with the increase in the rural residents' income and gradual change in their lifestyles, the mobility of residents has become increasingly diversified. Owing to the differences in development conditions, the rural residents' mobility also shows different characteristics in different counties and districts in the city. Qingyang City has the typical characteristics of urban and rural development in Western China and is thus a suitable case to study rural residents' mobility.

To further depict the spatial patterns and population differentiation of rural residents' urban-rural mobility, rural residents in Qingyang City and their employment characteristics are classified into three types: pure, part-time, and non-agricultural rural residents [61]. Rural residents who have lived in the countryside for a long time and only engage in farming and aquaculture are pure farming rural residents. Rural residents who engage in farming (aquaculture) but also carry out non-farming activities, such as working elsewhere for the rest of the year, are part-time rural residents. Rural residents who only serve agricultural enterprises are migrant workers, and those who engage in self-employed activities are identified as non-agricultural rural residents. 


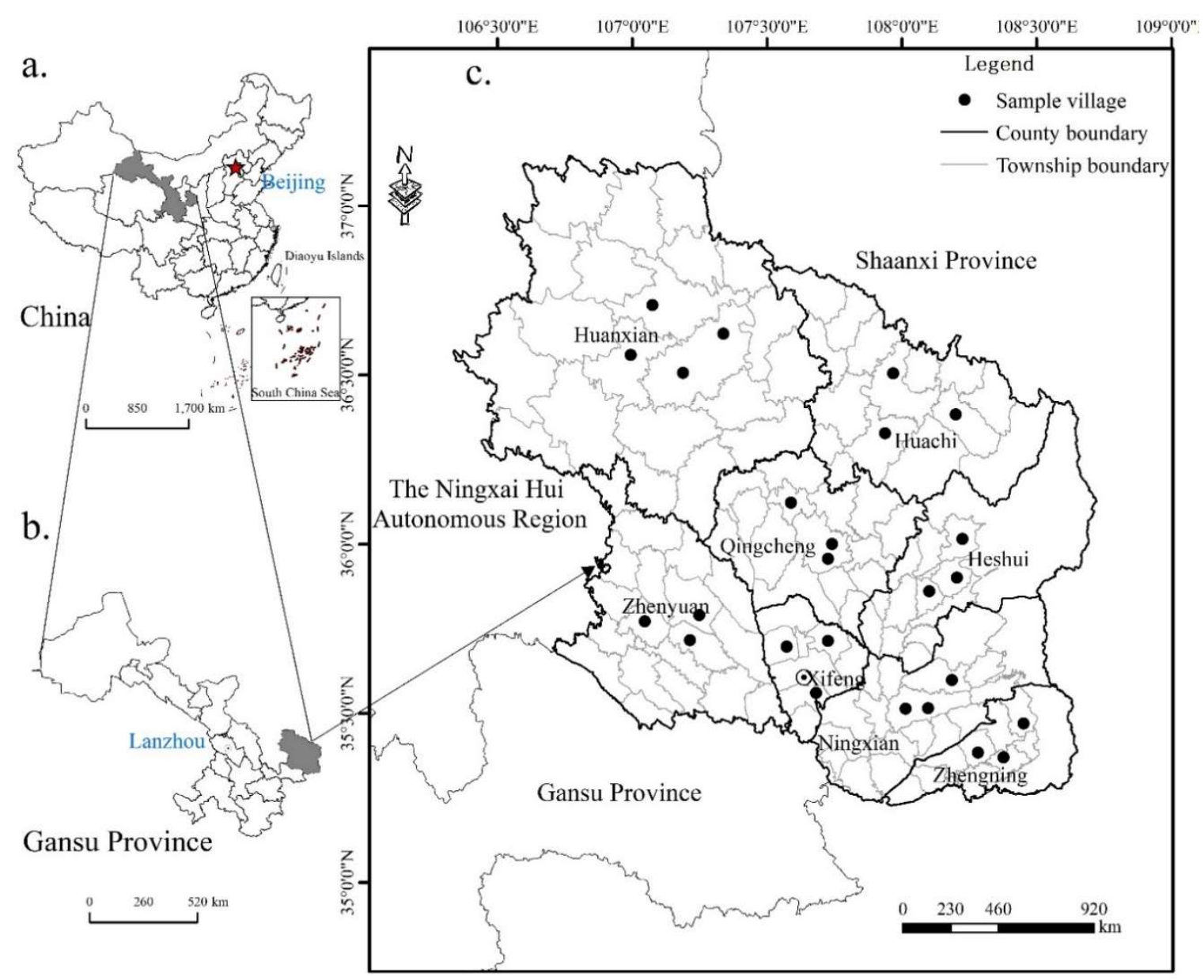

Figure 1. Distribution of surveyed villages in Qingyang, China.

\subsection{Theoretical Hypothesis: From Mobility to Sustainable Mobility}

During the course of the continuous evolution of history, technological innovation and its application have promoted continuous changes in the mode, distance, and frequency of residents' mobility and have thus changed the regional socio-economic and spatial organization. The specific socio-economic background is the starting point for understanding the concept of mobility. It is necessary to go beyond the movement and accessibility brought about by traffic improvement and connect mobility with residents' lifestyles, employment activities, and social interactions to understand the current mobility. Mobility is important for the integration of urban and rural development, which also reflects the ability of residents to survive and develop in the information era. For Western China, comprehensively considering the evaluation of rural mobility is particularly important.

Mobility is defined as the possibility of individual or group movement, which does not necessarily translate into travel [3,62]. It is closely related to transport systems and actor characteristics [57], and more attention is paid to how actors establish relationships with space [62]. The progress of information communication technology (ICT) and other technologies improves mobility and expands its connotations. With the application of ICT in the economic and social development of urban and rural areas, the concept of mobility can no longer satisfy the position changes of people or other factors. Moreover, its evaluation is not limited to mobility intensity and efficiency but should explore the broad social and economic connotations on the basis of people's needs.

Under the background of people-oriented smart city initiative, we argue that the evaluation of rural residents' mobility should emphasize the impact of informatization in terms of its indispensable role in rural life and production. At the same time, the experiences and feelings in the process of flow, such as satisfaction, should be included in the mobility evaluation. Therefore, from a systematic point 
of view, as well as considering the daily activities and travel of rural residents, rural mobility is defined as follows:

- Network mobility

Under the "space of flow" framework, urban and rural areas increasingly form a complex network system with close connections, and residents' mobility is one of the most active and key elements of this network relationship $[63,64]$. Therefore, we took the behaviors and activities of rural residents as the starting point, analyzed the travel and activity indicators of rural residents and evaluated the socio-economic network links among different types of residents and the characteristics and network support of residents at different scales of villages, towns, and cities as the core contents of rural mobility.

- Green mobility

With the increase in global greenhouse gas emissions, green development has become a global strategic choice. Under the framework of green cities, it is extremely important to ensure that green mobility is present, which involves government and individual decision-making [65]. In 2012, the central government of China put forward the development goal of "intensive and efficient production space, moderate living space and beautiful ecological space" through balanced and coordinated development of multiple social economic elements. The ecological environment in Western China is inherently fragile, and green and sustainable development is urgently needed. Therefore, incorporating green concepts, green production, green life, and green travel into the mobility evaluation of rural residents is important to allow an objective evaluation of the daily travel status of rural residents in Western China and to promote sustainable mobility.

- $\quad$ People-oriented mobility

People should be the core element, that is, mobility should be evaluated around people's own needs and experiences of mobility. Previous studies have recognized this point, but no in-depth discussion has been carried out $[27,28]$. Therefore, under the new concept of people-oriented and harmonious development, people-oriented mobility emphasizes equal living standards and quality of life shared by rural and urban residents, fair and comfortable mobility experience, equal enjoyment and dissemination of ideas, care, and innovation.

- Smart mobility

Although this concept is fashionable, and no unified understanding exists in academia, previous studies have emphasized a comprehensive and smarter future traffic service in combination with smart technology. While recognizing that such technology is multidisciplinary $[66,67]$, we must evaluate its connotations in light of problem orientation [68]. For rural areas in Western China, smart technology has only just entered residents' daily lives and activities. However, similar to this context, population distribution is unbalanced, infrastructure service is poor, and the existing transportation system is imperfect. Thus, smart technology is required to compensate for such limitations. Accordingly, here, smart mobility emphasizes the improvement of rural residents' mobility efficiency under the support of ICT, which is manifested in the application of new technologies in life and travel and learning ability in the face of uncertainty.

\subsection{Questionnaire Design and Data Acquisition}

Questionnaire surveys are an important method of acquiring data on urban and rural residents' travels and activities. Although big data have been used to analyze residents' spatial and temporal activities in recent years [69], traditional questionnaires and interviews still have their unique advantages [70]. The questionnaire used in this study comprised the socio-economic attributes of rural residents, daily travel modes and activities (e.g., origin, destination, travel, and content). 
A total of 209 questions were included in the questionnaire. This study analyzed the content and spatial characteristics of rural residents' daily activities using the questionnaire.

Considering the difficulty of communicating exclusively through written language, data acquisition involved a combination of household questionnaire surveys and face-to-face interviews with rural residents. The initial version of the questionnaire was first tested in a pilot survey, and an improved version was employed for the final survey. From July to September 2018, the research team conducted a household survey on the daily behaviors and activities of rural residents in Qingyang City, Gansu Province for three months. Based on the population size and socio-economic development level of each county (district), 25 typical villages were selected for the household survey (Figure 1). These villages represented the basic characteristics of the county (district) in terms of natural conditions, agricultural production, and transportation location. In each village, 40 people were randomly gathered by the village head, and face-to-face questionnaire survey and interviews were then conducted. Questionnaires were filled out by the investigator in accordance with the residents' answers. The interview time for each person was approximately $1 \mathrm{~h}$. Finally, 883 valid questionnaires were obtained, with a $100 \%$ recovery rate and an $88.30 \%$ validity rate.

The questionnaires were distributed equally among seven counties and one district. Of the 883 valid questionnaires collected in this survey, 578 respondents were women $(65.46 \%)$ and 305 were men $(34.54 \%)$. The survey was conducted in villages. Given that most of the men leave for work, the proportion of women who completed the survey was higher. Among them, there were $116(13.14 \%)$ part-time workers, $507(57.42 \%)$ non-agricultural rural residents, and $260(29.44 \%)$ pure rural residents. In terms of age, 170 were aged 16-30, accounting for $19.25 \%$ of all respondents, 386 were aged $30-45$ $(43.71 \%), 285$ were aged $45-60(32.28 \%)$, and 42 people were over 60 years old $(4.76 \%)$. In terms of educational level, 65 people attended primary school (7.36\%), and 201 were primary school graduates $(22.76 \%)$. The number of junior high school graduates was the largest at $419(47.25 \%)$, and 91 people obtained a high school education (10.31\%). A total of 49 people were secondary school graduates, accounting for $5.55 \%$. There were thirty-five college graduates, accounting for $3.96 \%$ of the respondents. A total of 22 people were undergraduates, accounting for $2.49 \%$ of all respondents. Only one person held a postgraduate degree and above, accounting for $0.11 \%$ of all respondents. The proportion of peasant households with high school or higher education level was very small, which is consistent with the actual situation of the local rural educational level. Moreover, the educational level of local peasant households was generally low.

\subsection{Measurement of Mobility}

Firstly, this study established a set of index systems to evaluate rural mobility. Secondly, it used data standardization to eliminate dimensions of varied data. Then, it employed the weighted summation method to obtain a comprehensive rural mobility index.

\subsubsection{Index System}

Indicators are capable of generating information for decision-making processes, which help to track and monitor the goals, benefits, efficacy, and efficiency of the proposed actions [71]. Various indices have been developed over the years to measure and evaluate mobility $[66,67,72-75]$. By using a mobility index "for evaluating transportation in cities at the macro-level", Moeinaddini et al. evaluated the private motorized mobility in Hong Kong and Chicago [67]. Garau et al. also constructed a synthetic urban mobility indicator to assess the infrastructures of different transport services, including public transport, cycle lines, bikes and car sharing, and the technological tools available to support mobility [66].

Therefore, a problem-oriented and goal-oriented evaluation index system is needed [68,76-79]. Accordingly, 27 indicators were established from four aspects-network, green, people-oriented, and smart mobility. A comprehensive measurement index system of rural residents' mobility was then constructed (Table 1). 
Table 1. Descriptive statistics of the sample.

\begin{tabular}{|c|c|c|c|c|c|}
\hline Variables & $\begin{array}{l}\text { Number of } \\
\text { Respondents }\end{array}$ & Percentage (\%) & Variables & $\begin{array}{l}\text { Number of } \\
\text { Respondents }\end{array}$ & $\begin{array}{c}\text { Percentage } \\
(\%)\end{array}$ \\
\hline Gender & & & Education & & \\
\hline Male & 305 & 34.54 & Below primary school & 65 & 7.36 \\
\hline Age & & & Junior high school & 419 & 47.45 \\
\hline $16-30$ years old & 170 & 19.25 & High school & 91 & 10.30 \\
\hline $31-45$ years old & 386 & 43.71 & Technical secondary school & 49 & 5.55 \\
\hline Personal Income & & & Master's degree or higher & 1 & 0.11 \\
\hline Below RMB 5000 & 297 & 33.87 & Residence & & \\
\hline RMB 5000-10,000 & 155 & 17.67 & Xifeng District & 114 & 12.91 \\
\hline RMB $10,000-15,000$ & 131 & 14.94 & Qingcheng County & 114 & 12.91 \\
\hline RMB $15,000-20,000$ & 100 & 11.40 & Heshui County & 111 & 12.57 \\
\hline Part-time rural residents & 116 & 13.14 & Huanxian County & 113 & 12.80 \\
\hline Non-agricultural rural residents & 507 & 57.42 & & & \\
\hline
\end{tabular}

The evaluation of network mobility can be measured from four aspects-mobility scale, mobility intensity, mobility density, and mobility centrality. Eight variables-including the mobility radius, mobility frequency, mobility node, and the node with the highest mobility frequency-were used to measure the network mobility.

In order to evaluate the green mobility of rural residents more completely, this paper explains the green mobility from four aspects - green concept, green production, green life, and green travel—and tries to incorporate the rural residents' understanding of the concept of green development and green behavior into the evaluation of the mobility, which is the logical way of thinking. Whether or not rural residents buy green ecological food in their daily lives is influenced by the concept of green development on their daily behaviors. Whether or not rural residents are willing to grow green organic food, use ecological organic feed, and know how to deal with domestic waste are all important components of green production and green life, as well as green mobility. In terms of green travel, this paper measured the green traffic mode, which can reflect the current situation of rural residents' travel in Western China.

People-centered mobility analysis is very important and can be explained from two aspects, rural residents' satisfaction and sense of acquisition, including satisfaction with personal social status, transport and human settlement environment, and the influence of learning and training on future life and work. The evaluation of this dimension pays more attention to measuring the effect of rural residents' mobility from the psychological level, which is very important for relatively weak rural residents.

Smart mobility reflects the use of information technology in rural residents' daily lives and travel, which is reflected by three aspects—smart equipment, smart travel, and smart life. The number of smart phones owned by families and the number of computers owned by families reflect the smart equipment situation. The use of the Internet to search for traffic information and navigate APP (Application) reflects the smart travel of rural residents. Smart life is measured by residents' QQ/WeChat usage rate and the popularity of online shopping.

Apart from considering the traditional indicators, such as accessibility, frequency, and intensity of travel, the index system also incorporates the relative rural informatization infrastructure and application, residents' informatization in production and life, network application, and rural residents' learning ability, among others. The novelty of this research lies in the new explanation of the connotations of rural mobility and the corresponding synthetic evaluation index system. 


\subsubsection{Data Standardization}

To eliminate the influences of dimensions on the evaluation results, the standardized method of decimal scaling was employed to standardize the assigned data:

$$
z_{i j}=\frac{x_{i j}}{10 \times p}
$$

where $Z_{i j}$ is the standardized value of the $j$ index in sample $i, X_{i j}$ is the value of index $j$ in sample $i$, and $P$ is the smallest integer satisfying the condition.

After standardization, the values of data are between 0 and 1 , which make the data comparable and conducive to the analysis. The more the calculated value tends to be 1 , the higher the mobility level is; the more the value tends to be 0 , the lower the mobility level of the index is.

\subsubsection{Weight Calculation}

The entropy method is a relatively objective method for calculating weights. This method considers the characteristics of indicators and does not include the relationships between indicators. In this study, the weights were determined in accordance with the improved entropy method [80,81]. The calculation formula was as follows:

$$
E_{i j}=-\frac{1}{\ln N} \sum\left(Z_{i j} \ln Z_{i j}\right)
$$

where $E_{i j}$ is the information entropy of index $j$ in sample $I$, and $N$ is the number of samples.

The formula used to calculate weight $W_{i j}$ was as follows:

$$
W_{i j}=\frac{1-E_{i j}}{\sum\left(1-E_{i j}\right)}
$$

The results of the weight calculations are shown in Table 2.

\subsubsection{Mobility Index}

By using the weighted summation method, we obtained the sub-mobility rural residents' index using the following calculation formula:

$$
F_{i}=\sum_{j=1}^{m} Z_{i j} W_{i j}
$$

where $F_{i}$ is the value of each sub-system mobility index, $m$ is the number of elements contained in the sub-system mobility index, $Z_{i j}$ is the standardized value of the $j$ index in sample $i$, and $W_{i j}$ is the weight of index $j$ in sample $i$.

On the basis of the subsystem mobility index, the synthetic mobility index (SMI) was obtained through weighted summation using the following calculation formula:

$$
F=\sum_{j=1}^{p} F_{i} \times Q_{i}
$$

where $F$ is the SMI of rural residents, $F_{i}$ is the value of each sub-system mobility index, $Q_{i}$ is the weight of each factor in the index layer, and $p$ is the number of subsystem indices contained in the SMI. 
Table 2. Index system for the comprehensive assessment of the mobility of rural residents.

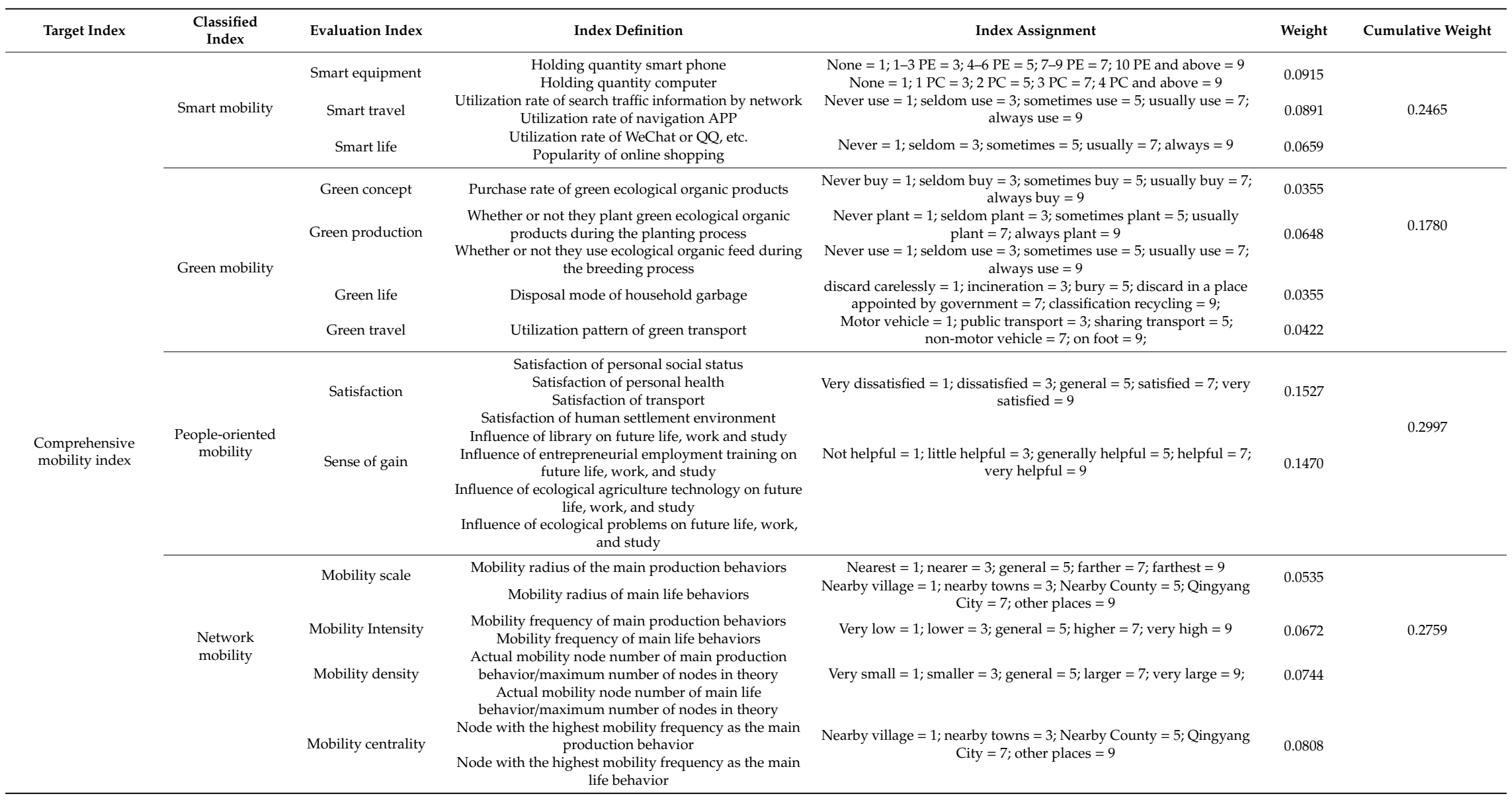




\section{Analysis of Results}

\subsection{SMI}

The mobility level of rural residents in Qingyang City is low, with an average SMI of 0.3146 . The SMIs of rural residents in different districts and counties are also low. A few differences exist among the SMIs of each district and county. Relatively, 37.5\% of the counties (districts) with a low mobility level and $50 \%$ of the counties (districts) with a medium or low mobility level account for $87.5 \%$ of the total number of counties (districts) in the study area (Figure 2). From the entire urban area of Qingyang, SMI has a three-level gradient with a gradual decline from the east to the west, and the mobility level shows obvious spatial agglomeration and major economic linkages. Among them, residents in Heshui and Huachi counties in the east have the highest SMIs of rural residents at 0.3304 and 0.3298 , respectively. The two counties have vigorously developed modern tourism in recent years. Moreover, the policy of benefiting from agriculture has significantly improved, resulting in high green and humanistic mobilities. In contrast, Zhenyuan County in the southwest and Huanxian County in the northwest have the lowest SMIs of rural residents at 0.2986 and 0.3029 , respectively (Figure 3). This finding is attributed to the relatively low traffic accessibility in the two counties and the low mobility of network and intelligence.

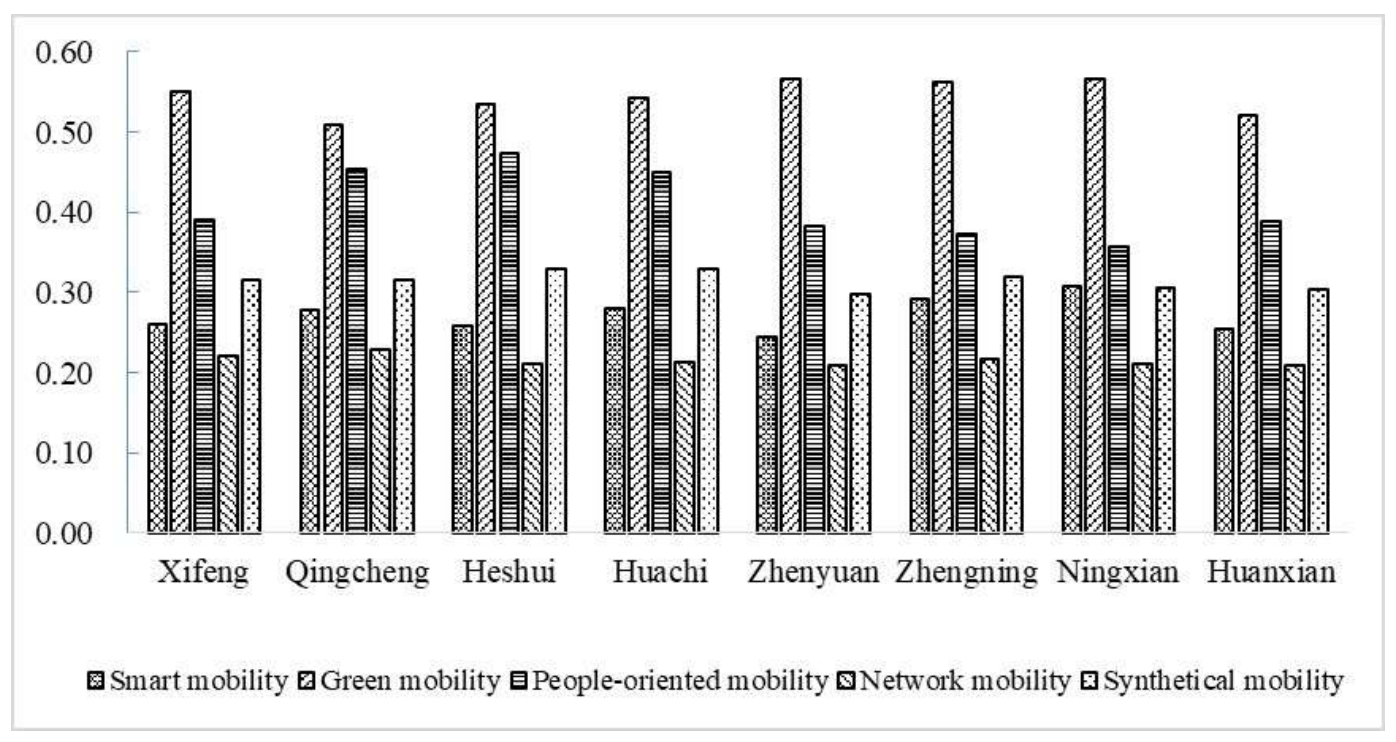

Figure 2. Mobility index of counties (districts) in Qingyang. 

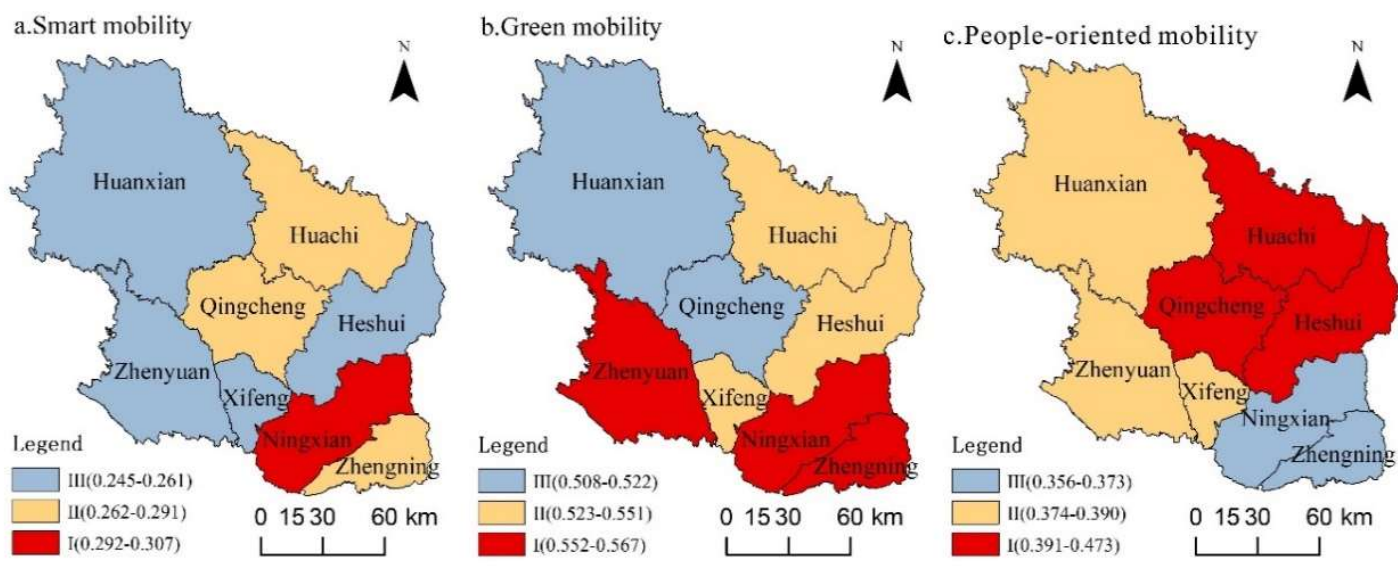

d.Network mobility

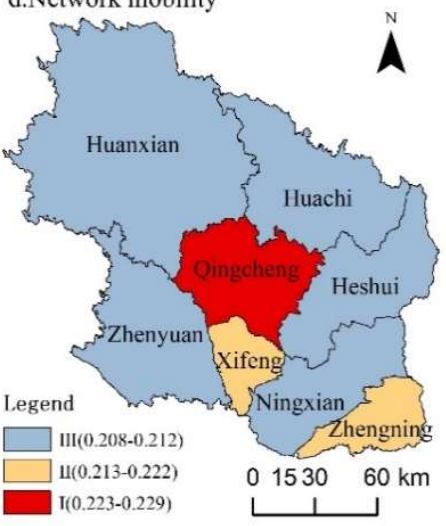

e.Synthetical mobility

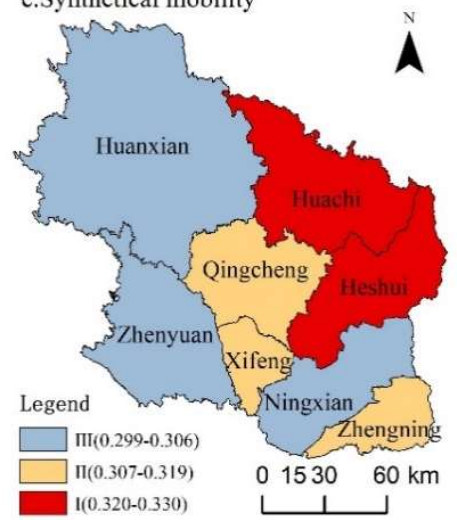

Figure 3. Spatial differences in the rural synthetic mobility index (SMI) of counties (districts) in Qingyang.

Among the different types of rural residents, part-time rural residents have the highest SMI (0.3232), and pure rural residents have the lowest SMI (0.3136). In addition, the SMI of non-agricultural rural residents is between those of pure and part-time rural residents (Figure 4). The distribution of SMIs among the different types of rural residents is consistent with their occupational characteristics, which fully reflects the impact of employment characteristics on rural residents' mobility. For example, the high mobility of part-time rural residents is determined by their production and living behaviors. Qingyang City is located in the gully area of the Loess Plateau. Guaranteeing the livelihoods of farmers through income from traditional agricultural land practices is difficult. To seek good income, they choose to enter cities and towns for other opportunities. Limited by their academic qualifications and abilities, the jobs they obtain are often laborious and unstable with low incomes and a lack of social care. Settling down in cities and towns is difficult for them owing to economic level and personal homesickness. At the same time, to complete agricultural production, part-time rural residents can only choose "migratory migration". This phenomenon often renders their frequency and distance of mobility higher than that of other rural residents and their SMIs are the highest. Pure rural residents have a strong dependence on land, small production, and living areas. Moreover, they are concentrated in villages and towns, with the lowest level of comprehensive mobility (Figure 4). 


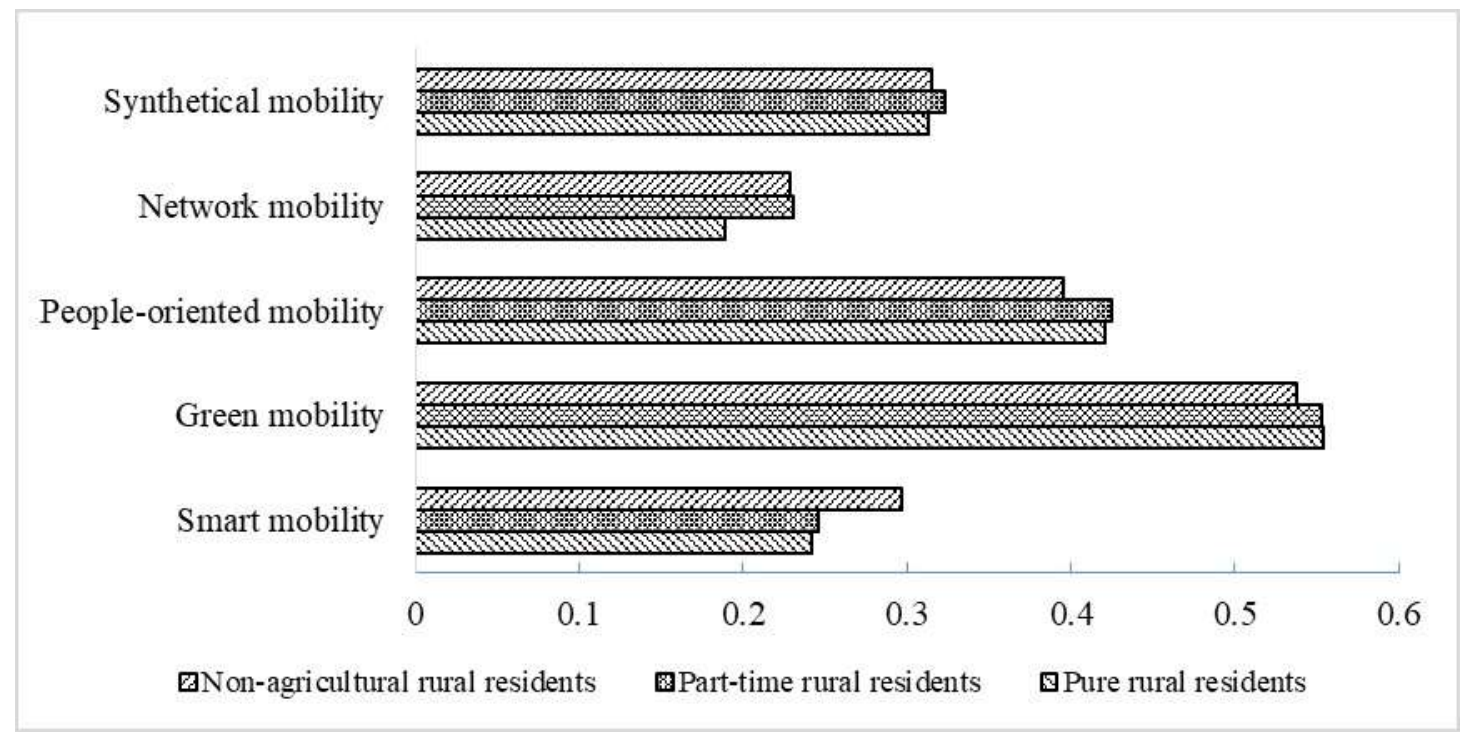

Figure 4. Mobility indexes of the different types of rural residents in Qingyang.

\subsection{Network Mobility}

Network mobility is the basic index used to measure rural residents' spatial mobility, which reflects the frequency, intensity, and spatial relationships of rural residents' travel and activities. The analysis shows that the city's network mobility index is 0.2149 . Compared with the other three dimensions of mobility, the network mobility index is the lowest of the entire city. Consequently, the latter also directly lowers the overall rural mobility index of the entire city. In terms of the network mobility index, Qingyang City presents an obvious center-periphery spatial trend. Within the city, Qingcheng County and Xifeng District in the central region are high-value areas that benefit from the advantages of transportation accessibility, whereas the other surrounding counties are low-value areas. Rural residents in Qingcheng County have the highest network mobility index values (0.2285). On the one hand, Qingcheng County is located in the geographical center of Qingyang City with many important traffic arteries running through it. Accordingly, the latter creates superior traffic conditions, and it is convenient for rural residents to leave it. On the other hand, Qingcheng County is the largest oil and gas development base in the Shaanxi-Gansu-Ningxia Region, which can provide rural residents with several part-time opportunities. Therefore, to maximize multiple benefits, many rural residents in the county often choose the part-time mode to consider income and agricultural production. Xifeng District had the second highest network mobility index (0.2216). As the political, economic, and cultural center of Qingyang City, Xifeng District also has the highest traffic accessibility with a large amount of rich commercial, educational, and medical resources. Thus, it supplies several livelihood choices for rural residents. Several rural residents enter the city to seek a better life, and daily mobility is frequent. In contrast, Huanxian County (0.2083), located in the western part of Qingyang City, is located far away from the central area of the city. Thus, rural residents have difficulty accessing job opportunities. At the same time, Huanxian County is the county with the lowest annual average total precipitation in Qingyang City, which means that it has poor agricultural production conditions. Rural residents need long farming cycles to ensure their income is sufficient with a short time to leave for work. Therefore, the network mobility index of rural residents is the lowest. Zhenyuan County (0.2094) has the same characteristics, with poor traffic conditions and a low average precipitation for many years. However, Zhenyuan County is connected with urban areas, and rural residents can easily leave for work. Thus, the network mobility index is slightly higher than that of Huanxian County.

From the perspective of the different types of rural residents, the network mobility index $(0.2308)$ of part-time rural residents is the highest. As part-time rural residents need to travel between rural and urban areas, the geographical scope of their production and living is the widest. Thus, the scale 
and degree of their mobility are obviously higher than those of the other types of rural residents. Non-agricultural rural residents no longer engage in agricultural production. The original land is handed over to others through circulation, rental, and other means by relatives and friends or through direct idle cultivation. Compared with part-time rural residents, the return frequency of non-agricultural rural residents is substantially reduced, and the daily flow is limited to the linear flow of residential and employment areas in cities and towns. Therefore, their network mobility index (0.2284) is slightly lower than that of part-time rural residents. The gully terrain and arid climatic conditions in Qingyang City mean that a significant amount of time is required for agricultural production, whereas the terrain restricts the development of transportation. Therefore, pure rural residents are bound to the land, and the scope of production and leisure life is small. The network mobility index (0.1889) of pure rural residents is far lower than that of part-time and non-agricultural rural residents. According to the data on rural residents' mobility, pure rural residents use villages as absolute agglomeration centers in production mobility because they engage in agricultural activities. Moreover, most of the required means of production can be met at the village level. Certain means of production such as seeds, fertilizers, and agricultural machinery, must be obtained at the township and county. In terms of the living mobility and agglomeration of pure rural residents, the township level occupies the largest share. Notably, the latter can basically meet the living needs of pure rural residents. The area at the county level also occupies a large share of the life flow of pure rural residents because it can meet other needs, such as the need to purchase advanced household appliances and transportation equipment. The production flow of part-time rural residents is obviously concentrated in the town areas. Thus, most part-time rural residents work in a relatively close distance, thereby allowing them to consider agricultural production. By contrast, the long-distance cross-city and cross-province workers are very few. Townships and counties exist as two agglomeration centers for part-time rural residents. Compared with pure rural residents, part-time rural residents have a wider range of life mobility. For non-agricultural rural residents who no longer engage in agricultural production activities, regardless of production or living mobility, the agglomeration centers are located in urbanized county areas or districts. This phenomenon indicates that the connection between non-agricultural rural residents and rural areas has weakened, and these residents are slowly integrating into urban life.

\subsection{Green Mobility}

Green mobility reflects the green level of rural residents' production and life, which is an important indicator of sustainable life in rural areas. Qingyang City is located in the Loess Hilly area, which has an extremely fragile ecological environment. Accordingly, the rural residents' overall awareness of green development in this area is high. Coupled with the implementation of the relevant policies of the central and local governments, the formation of green behavior habits among rural residents is objectively promoted. The city's green mobility index is 0.5441 , which is higher than that of the other three aspects of mobility. The spatial differentiation of rural residents in different counties and districts at the level of green mobility is unclear (Figure 3). The high-value areas are distributed in Ningxian County, Zhengning County in the southeast region, and Zhenyuan County in the southwest region. Xifeng District in the central region, and Huachi and Heshui in the northern regions are the median areas. Huanxian and Qingcheng are the low-value areas. The county with the highest green mobility index is Zhenyuan County (0.5670), followed by Ningxian County (0.5658). The lowest value appears in Qingcheng (0.5084). The green mobility index is directly related to rural residents' modes of production and lifestyle. Zhenyuan and Ningxian are traditional labor export counties. Apart from bringing back additional income, the peasant households who leave for work also bring other advanced production and living concepts, especially green production awareness, into their villages. At the same time, Zhenyuan and Ningxian are traditionally rich in green agricultural products, which further promotes the adoption of green production methods and green fertilizers in agricultural production by farmers. All of these factors improve the green mobility of rural residents. 
From the perspective of different types of rural residents, the green mobility index (0.5543) of pure rural residents who only engage in agricultural production is the highest, followed by part-time rural residents (0.5525) and non-agricultural rural residents (0.5376). Pure rural residents still depend on cultivation and aquaculture for their production activities. Moreover, their green production level is higher than that of part-time and non-agricultural rural residents. With the improvement in rural residents' income levels and the advancement of Beautiful Rural Projects initiated by the Chinese Government, the green living standard of pure rural residents is also steadily improving. In contrast, non-agricultural rural residents' production activities have completely turned to work in cities and towns. Their green living standards have increased with the help of better infrastructure and advanced green living consciousness in cities and towns. However, owing to the higher frequency of traffic trips and the increased distance, compared with pure rural residents, their green mobility index is relatively low (Figure 4).

\subsection{People-Oriented Mobility}

People-oriented mobility indicates rural residents' satisfaction within travel, including leisure, transportation and environment, and their sense of acquisition in different kinds of training and use of various cultural resources. Among the four dimensions of mobility, the people-oriented mobility index is 0.4086 . The spatial differentiation of rural residents' mobility in different counties and districts within the city is obvious. The areas with high levels of human mobility are Qingcheng County in the central region, as well as Heshui and Huachi counties in the northern region. In contrast, the low-value areas are the Ningxian and Zhengning counties in the southeast region. The highest people-oriented mobility indexes are 0.4728 in Heshui County and 0.3563 in Ningxian County. The highest value is 1.33 times that of the lowest value, which indicates a significant change in terms of the numerical value. From the regional point of view, Qingcheng and Huachi counties, which are in high-value areas, have vigorously developed their tourism industries in recent years. Two national $4 \mathrm{~A}$ grade tourist attractions have been created, which supply good places for rural residents' employment and leisure activities. Moreover, the life satisfaction of their residents has been substantially improved.

From the perspective of rural residents, the people-oriented mobility index of part-time rural residents (0.4252) is the highest, it is slightly lower for pure rural residents $(0.4210)$ and the lowest for non-agricultural rural residents (0.3954). Thus, non-agricultural rural residents have the lowest satisfaction and the worst sense of achievement. Despite the desire to settle in cities and towns, non-agricultural rural residents with low educational backgrounds and insufficient skills often feel pressure in the face of high housing prices and living costs. Enjoying many preferential agricultural policies is also difficult for them because they no longer engage in agricultural production. The part-time rural residents with the highest indexes of people-oriented mobility obtain high incomes by working outside, as the latter simultaneously assists them in mechanizing, modernizing, and scaling agricultural production. The income of agricultural production is also rising synchronously, thereby leading to an expected rise in the satisfaction and sense of acquisition in mobility. According to the survey data, pure rural residents have the lowest satisfaction with the transportation and leisure facilities in the village. Although $63 \%$ of the rural residents think that the library is helpful to their life, only $32 \%$ of the rural residents stated that libraries exist around their residence.

\subsection{Smart Mobility}

Smart mobility reflects the ability of rural residents to use modern information and communication technology and to acquire and transmit information, which implies the impact of informatization on their lives and production. The level of rural informatization in Qingyang City is low, which also affects the development of rural residents' smart mobility. Qingyang's rural smart mobility index is 0.2719. However, obvious differences exist in the SMIs between districts and counties within the city area (Figure 3). In the eastern region, including Ningxian and Zhengning counties, the level of smart mobility is high with mobility indices of 0.3071 and 0.2912 , respectively. In the western 
region, including Zhenyuan and Huanxian counties, the level of smart mobility is low with mobility indices of 0.2452 and 0.2547 , respectively. In contrast, in the northern region, including Qingcheng and Huachi counties, the smart mobility is of a median level. The difference in the smart mobility index in counties and districts has a certain relationship with the preferred work places of rural residents. The eastern rural residents mostly search for work in large cities, especially Xi'an (the capital of the Shaanxi Province). Meanwhile, the central rural residents mostly go to Xifeng District or Qingcheng County for the same reason. Rural residents in the north and west often find work at Pingliang-another district-level city in Gansu Province-and Wuzhong City and Yinchuan City in the Ningxia Hui Autonomous Region. Rural residents who work in other developed cities tend to have high incomes and stronger ability to purchase electronic products, such as mobile phones and computers. At the same time, they are open-minded. They easily accept new information and communication technology and bring it back to the original rural areas. Notably, the latter brings a high level of smart mobility.

From the perspective of rural residents, the smart mobility index of non-agricultural rural residents (0.2967) is significantly higher than that of other types of rural residents, and that of pure rural residents (0.2415) is close to that of part-time farmers $(0.2462)$ but slightly lower than that of part-time rural residents (Figure 4). For many reasons, non-agricultural rural residents no longer engage in agricultural production. They begin to settle in cities and towns and slowly integrate into urban life. This type of group has exceeded pure rural and part-time rural residents in terms of the degree of information acquisition and acceptance, which renders the smart mobility index of non-agricultural households the highest. Considering that part-time rural residents leave for work for long periods of time, their area of activity is wider than that of pure rural residents. In addition, the number of times they go to cities and towns is high. Thus, they can have additional contact with advanced information facilities in cities and towns. At the same time, with open minds, they can popularize new things to their families, relatives, and friends, and promote their level of information. Compared with pure rural residents, part-time rural residents also spend more on information products such as computers and mobile phones (Figure 4).

\section{Discussion and Conclusions}

\subsection{Discussion}

In contrast to urban mobility, constant strengthening of the interpretation and evaluation of rural mobility is necessary. On the basis of the new social and economic conditions, technological background, and the existing literature, this study offers a new interpretation of the theoretical connotations of rural mobility. Taking Qingyang City in Western China as an example, the mobility of rural residents was analyzed and evaluated in this study.

In recent years, research on spatial mobility has begun to pay attention to the feelings involved in the process of flow, the use of new technology, and the impact on the surrounding environment. The latest literature discusses future sustainable mobility centered on green and smart mobilities [39]. Mobility is a comprehensive concept involving the displacement of human beings and the changes in social relations. In this era of global interconnections, mobility also encompasses opportunities for development and quality of life. For rural areas, although public services, accessibility, and other aspects are far from the city, discussing the smart mobility of rural areas is not a distant topic. This finding is especially true with the infiltration of information technology into rural residents' lives and production. At the same time, the increase in rural residents' travel has begun to affect the spatial patterns of urban and rural areas. Therefore, it is necessary to consider the subjective feelings and emotions of residents in terms of their satisfaction and sense of acquisition in mobility. The study proposes four explanations for future sustainable rural mobility, namely, network, green, humanistic and smart mobilities. This logic of interpretation is new as it transcends the concept of mobility evaluated from only distance and frequency perspectives. It intends to put rural mobility 
under the framework of humanism before establishing humanistic policy considerations in improving rural mobility.

Following the data of activities, the existing rural mobility research has partly studied residents' mobility, focusing on the mobility of vulnerable groups. As far as geography is concerned, the study of mobility has specific spatial attributes and problem orientations. It cannot be separated from the urban and rural geographic spaces under specific socio-economic conditions and the problems faced by rural residents in the process of mobility. Therefore, on the basis of theoretical explanation and from a systematic lens, this study constructed a comprehensive evaluation index system for rural mobility concerning the production and living mobility of rural residents. The social network connections, information access capability, infrastructure network, green behaviors, and satisfaction are included in the SMI system for rural residents to reflect the relationships between these aspects of residents' behavior and mobility. Evidently, for rural residents in economically backward countries or regions, mobility is closely related to livelihood problems [82]. This index system does not consider the livelihood-related indicators of rural residents and the mobility of special groups, especially the elderly and left-behind women. At the same time, this study did not consider the relationships between network mobility, people-oriented mobility, smart mobility, and green mobility. The analysis was not deep enough to measure all kinds of mobility. It only paid attention to the direction and frequency of different types of rural residents' mobility and did not pay attention to the improvement of the quality of rural residents' mobility. All these aspects need systematic and in-depth exploration in future research. Empirical studies in Qingyang City have shown that for rural areas in Western China, mobility should be incorporated into the local development strategies to consider strategies to promote the factors, flow, and integration of urban and rural systems. Under the framework of the "rural revitalization strategy", the integration and development of primary, secondary, and tertiary industries put forward by the central government has effectively promoted the transformation of the rural economy. On the one hand, we have witnessed increasing exchanges and interactions between urban and rural residents including migrant workers, graduates of secondary and higher education institutions, and scientific and technological employees with urban household registration, who have become the main forces of urban and rural population flow. These have provided the driving force to change the flow of urban and rural areas from a single to a two-way flow of residents from urban and rural areas. On the other hand, the differences in mobility among different types of rural residents still deserve our attention. Thus, the question remains: How do we simultaneously improve the efficiency of rural residents' mobility and the quality of residents' mobility?

\subsection{Conclusions}

By empirically studying the rural mobility in Qingyang City, Gansu Province, which is located in the Loess Hilly Region, this study verified the theoretical analytical framework and proposed an index system for rural mobility. This study divided the rural residents in the case area into three types, namely-pure, part-time, and non-agricultural rural residents. Subsequently, it evaluated the comprehensive mobility of rural residents and the mobility in various dimensions. The results reflect the current characteristics of the mobility of rural residents in the city and validate the effectiveness of the index system.

The SMIs of rural residents in Qingyang City and those of rural residents in the districts and counties of Qingyang City are low. Certain spatial differences exist, whether among municipalities or among districts and counties. From the perspective of regional space, SMI has obvious spatial agglomeration and main economic linkages. Compared with the different types of rural residents, part-time rural residents have the highest SMI values, and pure rural residents have the lowest SMI values. The SMI values of non-agricultural rural residents are between the two. The distribution of SMIs among the different types of rural residents reflects the differences in the residents' mobility in terms of employment characteristics. 
With respect to the different dimensions of mobility, the highest mobility index in Qingyang City is the green mobility index, followed by the people-oriented mobility index. In contrast, the smart and network mobility indices are low. The characteristics of Qingyang's green agriculture industry, the concept of green production, and the consumption behaviors of rural residents have increased the green mobility of rural residents. Rural residents improve their family income and quality of life by working and consuming in cities or towns. In recent years, the implementation of preferential policies, such as those concerning agriculture, the countryside and farmers, and the optimization of the rural human settlement environment have improved the rural residents' people-oriented mobility. As a typical representative of rural areas in Western China, Qingyang's deficiencies in information technology application, traffic accessibility, basic public services, and public financial resources restrict the improvement of smart and network mobilities. Thus, for rural areas in Western China, the application and popularization of urban and rural information technology and the construction of transportation infrastructure are obstacles to the improvement of rural mobility and the direction of future policy efforts.

Author Contributions: Conceptualization, C.L.; methodology, C.L.; software, B.Y.; validation, L.L. and C.L.; formal analysis, B.Y.; investigation, Y.Z. and B.Y.; resources, Y.Z.; data curation, B.Y. and Y.Z.; writing-original draft preparation, C.L.; writing - review and editing, C.L.; visualization, B.Y.; supervision, C.L.; project administration, C.L.; funding acquisition, C.L.

Funding: This research was funded by the National Natural Science Regional Foundation of China (41861034).

Conflicts of Interest: The authors declare no conflict of interest.

\section{References}

1. Castles, S.; Miller, M.; Ammendola, G. The age of migration: International population movements in the modern world, American foreign policy interests. J. Natl. Comm. Am. Foreign Policy 2005, 27, 537-542.

2. Massey, D.S.; Arango, J.; Hugo, G.; Kouaouci, A.; Pellegrino, A. Worlds in Motion: Understanding International Migration at the End of the Millennium; Clarendon Press: Oxford, UK, 1999.

3. Flamm, M.; Kaufmann, V. Operationalising the concept of motility: A qualitative study. Mobilities 2006, 1, 167-189. [CrossRef]

4. Castells, M. The Rise of the Network Society; Blackwell: Oxford, UK, 1996.

5. Lash, S.M.; Urry, J. Economies of Signs and Space; Sage: London, UK, 1994.

6. Larsen, J.; Urry, J.; Axhausen, K.W. Social networks and future mobilities. In Report to the UK Department for Transport; Lancaster University: Lancaster, UK, 2005.

7. Bracey, H.E. English Rural Life: Village Activities, Organisations and Institutions; Routledge and Kegan Paul: London, UK, 1959.

8. Milbourne, P.; Kitchen, L. Rural mobilities: Connecting movement and fixity in rural places. J. Rural Stud. 2014, 34, 326-336. [CrossRef]

9. Kamargianni, M.; Li, W.; Matyas, M.; SchaFer, A. A critical review of new mobility services for urban transport. Transp. Res. Procedia 2016, 14, 3294-3303. [CrossRef]

10. Chen, C.; Bo, Q. The emergence of China's middle class: Social mobility in a rapidly urbanizing economy. Habitat Int. 2014, 44, 528-535. [CrossRef]

11. Zhang, J.H.; Yu, M.L.; Wu, F.W.; Chen, W. Human capital of family and social mobility in rural areas-Evidence from China. J. Integr. Agric. 2013, 12, 1905-1915. [CrossRef]

12. Zhao, Y.Z.; Li, Y.J.; Heath, A.; Shryane, N. Inter-and intra-generational social mobility effects on subjective well-being-Evidence from mainland China. Res. Soc. Stratif. Mobil. 2017, 48, 54-66. [CrossRef]

13. Dalkmann, H.; Hutfilter, S.; Vogelpohl, K.; Schnabel, P. Sustainable mobility in rural China. J. Environ. Manag. 2008, 87, 249-261. [CrossRef]

14. Wenglenski, S. Daily mobility. The International Encyclopedia of Geography; John Wiley \& Sons: Somerset, NJ, USA, 2017.

15. Urry, J. Mobilities; Polity: Cambridge, UK, 2007.

16. Cresswell, T. On the Move: Mobility in the Modern World; Routledge: Abingdon, UK, 2006. 
17. Cresswell, T.; Merriman, P. (Eds.) Geographies of Mobilities: Practices, Spaces, Subjects; Ashgate: Farnham, UK, 2011.

18. Merriman, P. Mobility, Space and Culture; Routledge: London, UK, 2012.

19. Titheridge, H.; Achuthan, K.; Mackett, R.; Solomon, J. Assessing the extent of transport social exclusion among the elderly. J. Transp. Land Use 2007, 2, 31-48. [CrossRef]

20. Scheiner, J. Housing mobility and travel behaviour: A process-oriented approach to spatial mobility: Evidence from a new research field in Germany. J. Transp. Geogr. 2006, 14, 287-298. [CrossRef]

21. Brighenti, A.M. New media and urban motilities: A territoriologic point of view. Urban Stud. 2012, 49, 399-414. [CrossRef]

22. Kellerman, A. Daily Spatial Mobilities; Ashgate: Farnham, UK, 2012.

23. Kellerman, A. Potential mobilities. Mobilities 2012, 7, 171-183. [CrossRef]

24. Hanson, S.; Giuliano, G. (Eds.) The Geography of Urban Transportation; Guilford Press: New York, NY, USA, 2004.

25. Garrison, W.L.; Levinson, D.M. The Transportation Experience: Policy, Planning, and Deployment; Oxford University Press: New York, NY, USA, 2006.

26. Löfgren, O. Motion and emotion: Learning to be a railway traveler. Mobilities 2008, 3, 331-351. [CrossRef]

27. Schiefelbusch, M. Rational planning for emotional mobility? The case of public transport development. Plan. Theory 2010, 9, 200-222. [CrossRef]

28. Cao, J.; Wang, D. The association between travel and satisfactions with travel and life: Evidence from Twin Cities. In Mobility, Sociability and Well-Being of Urban Living; Springer: Berlin/Heidelberg, Germany, 2016; pp. 151-167. ISBN 978-3-662-48184-4.

29. Banister, D. The sustainable mobility paradigm. Transport Pol. 2008, 15, 73-80. [CrossRef]

30. Barr, S.; Prillwitz, J. Green travellers? Exploring the spatial context of sustainable mobility styles. Appl. Geogr. 2012, 32, 789-809. [CrossRef]

31. Borroni-Bird, C.E. Personal urban mobility for the twenty-first century. In Energy, Transport, \& the Environment; Springer: London, UK, 2012; pp. 313-334. ISBN 978-1-4471-2717-8.

32. Yang, J.; Guo, A.; Li, X.; Huang, T. Study of the impact of a High-Speed Railway opening on China's accessibility pattern and spatial equality. Sustainability 2018, 10, 2943. [CrossRef]

33. Yang, J.; Bao, Y.J.; Zhang, Y.Q.; Li, X.M.; Ge, Q.S. Impact of accessibility on housing prices in Dalian city of China based on a geographically weighted regression model. Chin. Geogr. Sci. 2018, 28, 505-515. [CrossRef]

34. Hunecke, M.; Haustein, S.; Böhler, S.; Grischkat, S. Attitude-based target groups to reduce the ecological impact of daily mobility behavior. J. Environ. Psychol. 2010, 42, 3-43. [CrossRef]

35. Benevolo, C.; Dameri, R.P.; D'Auria, B. Smart mobility in smart city. In Empowering Organizations; Lecture Notes in Information Systems and Organisation; Torre, A., Braccini, R., Spinelli, Eds.; Springer: Cham, Switzerland, 2016.

36. Lam, D.; Head, P. Sustainable urban mobility. In Energy, Transport, E the Environment; Springer: London, UK, 2012; pp. 359-371. ISBN 978-1-4471-2717-8.

37. Ureta, S. Mobilising poverty? Mobile phone use and everyday spatial mobility among low-income families in Santiago, Chile. Inf. Soc. 2008, 24, 83-92. [CrossRef]

38. Rye, J.F. Labour migrants and rural change: The "mobility transformation" of Hitra/Frøya, Norway, $2005-2015$. J. Rural Stud. 2018, 64, 189-199. [CrossRef]

39. Stockdale, A. Residential mobility patterns in rural Northern Ireland-clean break or more of the same? Scott. Geogr. J. 1993, 109, 32-36. [CrossRef]

40. Porter, G. Living in a walking world: Rural mobility and social equity issues in sub-Saharan Africa. World Dev. 2002, 30, 285-300. [CrossRef]

41. Nutley, S. Monitoring rural travel behaviour: A longitudinal study in northern Ireland 1979-2001. J. Transp. Geogr. 2005, 13, 247-263. [CrossRef]

42. Pucher, J.; Renne, J.L. Rural mobility and mode choice: Evidence from the 2001 national household travel survey. Transportation 2005, 32, 165-186. [CrossRef]

43. Dashtestaninejad, H.; Vaziri, M.; Timmermans, H. Classification of rural residents on the basis of activity travel. Transp. Res. Rec. 2014, 2454, 20-27. [CrossRef]

44. Philip, M.; Sreelatha, T.; Soosan, G.T. An activity based characteristic study on travel behavior of rural. Int. J. Innov. Res. Sci. Eng. Technol. 2013, 2, 2870-2875. 
45. Vaziri, M.; Dashtestaninejad, H.; Asgari, H.; Salimi, F. Rural travel behaviour in developing countries: A study of farm-based villages in Iran. Policy Res. Work. Pap. 2014, 1, 25-45. [CrossRef]

46. Millward, H.; Spinney, J. Time use, travel behavior, and the rural-urban continuum: Results from the Halifax STAR project. J. Transp. Geogr. 2011, 19, 51-58. [CrossRef]

47. Yen, I.H.; Flood, J.F.; Thompson, H.; Anderson, L.A.; Wong, G. How design of places promotes or inhibits mobility of older adults: Realist synthesis of 20 years of research. J. Aging Health 2014, 26, 1340-1372. [CrossRef]

48. Zhang, L. Effects of urban and rural residents' behavior differences in sports and leisure activity: Application of the theory of planned behavior and structural equation modeling. In International Conference on Management Science E Engineering Management; Springer: Cham, Switzerland, 2017.

49. Olsson, J. Rural-urban spatial interaction in the global south: Long-distance mobility changes, desires and restrictions over two decades in rural philippines. Geogr. Ann. 2012, 94, 287-304. [CrossRef]

50. Farrugia, D. The mobility imperative for rural youth: The structural, symbolic and non-representational dimensions rural youth mobilities. J. Youth Stud. 2016, 19, 836-851. [CrossRef]

51. Koushki, P.A.; Berg, W.D. Improving rural mobility-A practical approach. Transp. Q. 1982, 36, 631-642.

52. Mattson, J.W. Aging and mobility in rural and small urban areas: A survey of north dakota. J. Appl. Gerontol. 2011, 30, 700-718. [CrossRef] [PubMed]

53. Farooq, A.; Kayani, A.K. Social dynamics in rural Punjab: Changes in gender roles, spatial mobility and decision making. Int. J. Sociol. Soc. Policy 2014, 34, 317-333. [CrossRef]

54. Plazinić, B.R.; Jović, J. Mobility and transport potential of elderly in differently accessible rural areas. J. Transp. Geogr. 2018, 68, 169-180. [CrossRef]

55. Bryceson, D.F.; Mbara, T.C.; Maunder, D. Livelihoods, daily mobility and poverty in sub-Saharan Africa. Transport Reviews. 2003, 23, 177-196. [CrossRef]

56. Ahern, A.; Hine, J. Rural transport-valuing the mobility of older people. Res. Transp. Econ. 2002, 34, 27-34. [CrossRef]

57. Seeborg, M.C.; Jin, Z.; Zhu, Y. The new rural-urban labor mobility in china: Causes and implications. J. Socio-Econ. 2000, 29, 39-56. [CrossRef]

58. Liu, C.; Wang, S.; Liu, H.; Zhu, W. The impact of china's priority forest programs on rural households' income mobility. Land Use Policy 2013, 31, 237-248. [CrossRef]

59. Liu, C.F.; Zhang, Z.Y. From town-country integration to urban-rural integration: New thinking on the relationship between urban and rural areas. Sci. Geogr. Sin. 2018, 38, 1624-1633. (In Chinese)

60. Liu, C.F.; Wang, C. Spatio-temporal evolution characteristics of habitat quality in the Loess Hilly Region based on land use change: A case study in Yuzhong County. Acta Ecol. Sin. 2018, 38, 7300-7311. (In Chinese)

61. Li, X.Y.; Zhang, A.L.; Gao, J.Y.; Qiao, R.F.; Chen, Y. Analysis on rural households' willingness in conversion of rural land to urban land: A case study of suburb and exurban in Wuhan. Resour. Environ. Yangtze Basin 2007, 16, 471. (In Chinese)

62. Bauman, Z. Liquid Modernity; Polity Press: Cambridge, UK, 2000.

63. Zhen, F.; Wei, Z. Influence of information technology on social spatial behaviors of urban residents-Case of Nanjing City in China. Chin. Geogr. Sci. 2008, 18, 316-322. [CrossRef]

64. Zhen, F.; Wang, B.; Wei, Z.C. The rise of the internet city in China: Production and consumption of internet information. Urban Stud. 2015, 52, 2313-2329. [CrossRef]

65. Szołtysek, J.; Otręba, R. Determinants of quality of life in building city green mobility concept. Transp. Res. Procedia 2016, 16, 498-509. [CrossRef]

66. Garau, C. Perspectives on cultural and sustainable rural tourism in a smart region: The case study of marmilla in Sardinia (Italy). Sustainability 2015, 7, 6412-6434. [CrossRef]

67. Moeinaddini, M.; Asadi-Shekari, Z.; Zaly Shah, M. An urban mobility index for evaluating and reducing private motorized trips. Measurement 2014, 63, 30-40. [CrossRef]

68. Alonso, A.; Monzón, A.; Cascajo, R. Comparative analysis of passenger transport sustainability in European cities. Ecol. Indic. 2015, 45, 578-592. [CrossRef]

69. Ahas, R.; Aasa, A.; Yuan, Y.; Raubal, M.; Smoreda, Z.; Liu, Y.; Ziemlicki, C.; Tiru, M.; Zook, M. Everyday space-time geographies: Using mobile phone-based sensor data to monitor urban activity in Harbin, Paris, and Tallinn. Int. J. Geogr. Inf. Sci. 2015, 29, 2017-2039. [CrossRef] 
70. Qin, X.; Zhen, F.; Gong, Y.H. Combination of big and small data: Empirical study on the distribution and factors of catering space popularity in Nanjing, China. J. Urban Plan. Dev. 2019, 145, 05018022. [CrossRef]

71. Villela, T.M.A.; Magalhães, M.T.Q.; Gomes, H.A.S.; Arruda, B.D.L.; Silveira, L.S. Metodologia para desenvolvimento e Seleção de Indicadores para planejamento de transportes. In Presented at 21st Annual Meeting of Brazilian National Association for Transport Research \& Education; ANPET: Rio de Janeiro, Brazil, 2007. (In Portuguese)

72. Caragliu, A.; de Bo, C.; Njkamp, P. Smart cities in Europe. Urban Insight 2011, 18, 65-82. [CrossRef]

73. Xi, G.L.; Zhen, F.; Shen, L.Z.; Wang, B. The evaluation of resident fluidity and the spatial characteristics of flow in Nanjing. Sci. Geogr. Sin. 2013, 33, 1051-1057. (In Chinese)

74. Debnath, A.K.; Chin, H.C.; Haque, M.M.; Yuen, B. A methodological framework for benchmarking smart transport cities. Cities 2014, 37, 47-56. [CrossRef]

75. Giffinger, R.; Fertner, C.; Kramar, H.; Kalasek, R.; Pichler-Milanovicć, N.; Meijers, E. Smart Cities: Ranking of European Medium-Sized Cities; Centre of Regional Science: Vienna, Austria, 2007.

76. Lopez Carreiro, I.; Monzon, A. Evaluating sustainability and innovation of mobility patterns in spanish cities: Analysis by size and urban typology. Sustain. Cities Soc. 2018, 38, 684-696. [CrossRef]

77. Ning, Z.; Xia, F.; Ullah, N.; Kong, X.J.; Hu, X.P. Vehicular social networks: Enabling smart mobility. IEEE Commun. Mag. 2017, 55, 16-55. [CrossRef]

78. Ausubel, J.H.; Marchetti, C.; Meyer, P.S. Toward green mobility: The evolution of transport. Eur. Rev. 1998, 6, 137-156. [CrossRef]

79. Gonzalez, M.C.; Hidalgo, C.A.; Barabasi, A.L. Understanding individual human mobility patterns. Nature 2008, 453, 779-782. [CrossRef]

80. Guo, X.G. Application of improved entropy method in evaluation of economic result. Syst. Eng. Theory Pract. 1998, 12, 98-102. (In Chinese)

81. Xu, H.S.; Chao, M.; Lian, J.J.; Xu, K.; Chaima, E. Urban flooding risk assessment based on an integrated k-means cluster algorithm and improved entropy weight method in the region of Haikou, China. J. Hydrol. 2018, 563, 975-986. [CrossRef]

82. Rantanen, T. Promoting mobility in older people. J. Prev. Med. Public Health 2013, 46, S50-S54. [CrossRef] [PubMed]

(C) 2019 by the authors. Licensee MDPI, Basel, Switzerland. This article is an open access article distributed under the terms and conditions of the Creative Commons Attribution (CC BY) license (http://creativecommons.org/licenses/by/4.0/). 